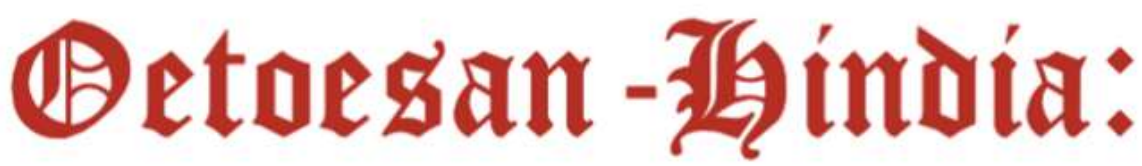 Telaah Pemikiran Kebangsaan
}

Volume 1 No 2 Tahun 2019 Hlmn. 69-78

Artikel Masuk: 3 Desember 2019 | Artikel Diterima: 31 Desember 2019

\section{Pandangan hidup dan alam pikiran orang melayu}

\author{
Bobby Briando ${ }^{\text {a1 }}$, Muhamad Ali Embi ${ }^{\text {b2 }}$ \\ ${ }^{\text {ab }}$ Universiti Utara Malaysia, Sintok, Kedah, Malaysia, 06010 \\ 1*bobby_briando@gsgsg.uum.edu.my, ${ }^{2}$ Ali@uum.edu.my \\ *surel korespondensi: bobby_briando@yahoo.com
}

\begin{abstract}
Abstrak
Pandangan hidup merupakan sebuah kristalisasi dari nilai-nilai yang dimiliki dan diyakini kebenarannya sehingga menimbulkan tekad untuk mewujudkan sesuatu yang menjadi tujuan akhirnya. Penelitian ini bertujuan untuk memberi visualisasi pandangan hidup Orang Melayu dalam berinteraksi dengan Tuhan, Sesama Hamba, Alam dan Diri Pribadi.Peneliti menggunakan pendekatan Budaya Melayu baik dalam bentuk syair atau gurindam untuk memvisualisasikan kehidupan Orang Melayu. Hasilnya adalah kehidupan Orang Melayu sejatinya selalu menjaga hubungan yang intim dengan Allah SWT, kemudian senantiasa menjaga hubungan harmonis dengan sesama manusia, serta cinta terhadap lingkungan dan menjaga marwah diri secara pribadi.
\end{abstract}

Kata Kunci: Pandangan Hidup; Budaya Melayu; Orang Melayu

\begin{abstract}
Way of life is a crystallization of the values that are owned and believed to be true so that raises the determination to realize something that becomes the final destination. This study aims to provide a visualization of Malay people's way of life in interacting with God, Fellow Servant, Nature and Personal Self. Researchers use the Malay Culture approach in the form of poetry or gurindam to visualize the life of the Malays. The result is that the lives of Malays actually always maintain an intimate relationship with Allah SWT, then always maintain a harmonious relationship with fellow human beings, as well as love the environment and maintain one's self-respect.
\end{abstract}

Keywords: Way of Life; Malayan Culture; Malay People

Hang Tuah

Tersebut sudah dalam hikayat

Laksmana Hang Tuah setia amanah

Menjunjung harkat juga zuriat

Jangan Melayu buang zuriat 
Pandangan hidup dan ....

Briando, B. \& Embi, M. A.

Dang merdu bunda berjasa

Melahirkan putra perkasa

Hang Tuah laksmana satria

Teladan negeri dan bangsa

Dari Bintan Kepulauan Riau

Gaung baktimu ke segenap rantau

Walau kini kau telah tiada

Fatwamu tiada 'kan sirna

Tuah sakti hamba negeri

Esa hilang dua terbilang

Patah tumbuh hulang 'kan berganti

Takkan Melayu hilang di bumi

Engkau susun jari sepuluh

Menghatur sembah duduk bersimpuh

Halus budi resah Melayu

Hang Tuah

Ho-o, Hang Tuah

Tuah...

“Tak 'kan Melayu hilang di bumi”. Itulah salah satu penggal bait lirik dalam judul lagu Hang Tuah karya maestro Melayu karya Husni Thamrin. Dalam bait tersebut besar harapan sang penggubah agar Melayu dapat terus hidup dan eksis di bumi Pertiwi. Melayu tidak hanya identik dengan nama suku namun lebih dari itu, Melayu adalah suatu cara pandang dalam menjalani hidup dan kehidupan. Pandangan hidup merupakan konsep dasar mengenai kehidupan yang dicita-citakan. Di dalamnya terkandung pikiranpikiran yang mendalam dan gagasan mengenai wujud kehidupan yang dianggap baik dan dapat dijadikan pedoman dalam mengarungi hidup (Briando, Triyuwono, \& Irianto, 2017).

Pandangan hidup merupakan sebuah kristalisasi dari nilai-nilai yang dimiliki dan diyakini kebenarannya sehingga menimbulkan tekad untuk mewujudkannya (Esram, 2010). Sementara itu alam pikiran adalah sesuatu yang timbul dalam benak, pikiran manusia, baik dengan renungan (intuisi) atau kontemplasi maupun berdasarkan gejala alam yang ada. Sesuatu yang terpikir akan diolah untuk kemudian diklasifikasikan, disistematiskan dan ditimbang masak-masak sehingga menjadi suatu formulasi yang utuh yang disebut sebagai idea pokok. Idea pokok ini bila dikembalikan kepada pemikiran yang sehat akan dapat diterima karena mengandung unsur logika, etika dan estetika (Suwardi, 1991). 
Dengan mengkaji pandangan hidup, dalam pandangan peneliti, akan tergambar ciri-ciri alam pikiran. Mengkaji proses tumbuhnya pandangan hidup dan alam pikiran lahirlah kehendak untuk berbuat, timbul sikap, dan lahirlah tingkah laku atau perilaku serta perbuatan(Suwardi, 1991). Masyarakat Melayu adalah penganut agama Islam, dengan demikian alam pikirannya tentu tidak terlepas dari sudut pandang Islam (Thamrin, 2015). Agama Islam yang dianut masyarakat Melayu sangat luas pengaruhnya dalam kehidupan sehari-hari, terutama memberikan acuan-acuan atau memberikan tuntunan-tuntunan dan ajaran-ajaran-ajaran untuk dapat menjalani hidup dengan selamat baik di dunia maupun di akhirat (Esram, 2010; Suwardi, 1991; Thamrin, 2015).

Menurut pandangan masyarakat Melayu, hidup ini adalah fitrah dan harus dijalani oleh setiap manusia, baik buruk hidup di dunia ini tergantung segala amalan yang dilakukan manusia. Di samping itu, masyarakat Melayu juga meyakini bahwa pada hakikatnya manusia hidup di dunia ini untuk mencari kebahagiaan dunia dan akhirat (Thamrin, 2015). Artinya, manusia dalam melakukan kegiatan sehari-hari harus berpegang kepada dua sisi kebutuhan, yaitu kebutuhan batiniah dan kebutuhan lahiriah. Kebutuhan batiniah adalah kebutuhan dalam mencapai ketenangan jiwa melalui jalur agama dengan semakin mendekatkan diri kepada Yang Maha Pencipta, Allah SWT. Sedangkan kebutuhan lahiriah adalah sebagai sarana ikhtiar dalam memenuhi kebutuhan hidup manusia sehari-hari seperti sandang, pangan dan papan. Kolaborasi kebutuhan tersebut akan menciptakan keseimbangan hidup yang pada akhirnya dapat menjadikan pribadi masyarakat Melayu menjadi pribadi yang unggul dan beriman (Esram, 2010; Suwardi, 1991).

Suwardi (1991) dalam sebuah karyanya yang berjudul 'Budaya Melayu Dalam Perjalanannya Menuju Masa Depan' mengategorikan hubungan manusia dengan Tuhan, manusia dengan lingkungan masyarakatnya, manusia dengan alam sekitarnya serta manusia sebagai pribadi sebagai kajian pandangan hidup dan alam pikiran masyarakat Melayu. Hal ini tidak terlepas dari keyakinan masyarakat Melayu bahwa Tuhan atau Allah SWT adalah Dzat yang Mahakuasa, yang menciptakan alam dengan seluruh isinya, termasuk manusia (Suwardi, 1991). Manusia sebagai makhluk ciptaan Tuhan berkewajiban mengabdi kepada-Nya, sesuai dengan firman-Nya berikut:"Dan aku tidak menciptakan jin dan manusia melainkan supaya mereka menyembah-Ku" (QS. Ad Dzaariyat: 56).

Peneliti menggunakan budaya Melayu dan menjadikan budaya tersebut dalam mensinergikan hubungan hama dengan Tuhan, Sesama Manusia, Alam dan Diri Pribadi. Penelitian ini bertujuan untuk memvisualisasikan kejeniusan lokal budaya Melayu dalam membentuk pribadi Orang Melayu. Tulisan ini ingin membahas mengenai nilai-nilai luhur yang seharusnya di angkat untuk kemudian dijadikan suatu panduan dalam bersikap dan bertingkah laku, sekaligus sebagai bantahan terhadap local foolness yang menganggap budaya lokal sebagai suatu kebodohan. Jika pembahasan terkait 
pandangan hidup atau way of life banyak berkiblat pada gaya barat, maka penulis mencoba untuk mengangkat nilai luhur Melayu sebagai suatu pandangan hidup (way of life) yang dapat dijadikan suatu pedoman dalam bertingkah laku dan bertindak, sehingga marwah Melayu tidak hanya menjadi slogan semata namun dapat diaplikasikan di kehidupan nyata.

\section{PEMIKIRAN}

Pembahasan pandangan hidup dalam ranah penelitian ilmiah sebelumnya pernah diteliti oleh Yusdita (2019) terkait rencana pembelajaran (untuk) peradaban yang membahas terkait pencerahan terhadap praktek pendidikan akuntansi yang terdistorsi dari pandangan hidup dan ideologi bangsa berdasarkan pada Pancasila dan ajaran Rasulullah Muhammad S.A.W. Hasil penelitian menunjukkan bajwa cara mengajar menggunakan pandangan hidup atau filosofis praktik yang menjaga habluminnallah dan habluminannas dapat dilakukan sebagai solusi terhadap fenomena perilaku anak yang terdegradasi. Penelitian lain dilakukan juga oleh Mulawarman (2019) terkait menghidupkan kembali semangat dan pandangan hidup H.O.S Tjokroaminoto sebagai centre of culture. Dalam artikel tersebut penulis menelurusi sepak terjang dan pandangan hidup Pak Tjokro berupa pemikiran dan aksi yang menghasilkan dua kata kunci, yaitu Hijrah dan Zelfbestuur. Pandangan hidup dan aksi tersebut dibutuhkan oleh Indonesia dalam membangkitkan spirit baru Berjiwa Jang Oetama yang Selalu Hidup.

Konsep Hubungan Manusia dengan Tuhan (Hablun Minallah). Menurut pandangan Orang Melayu, dalam pertumbuhan dan perkembangan manusia dari sejak adanya telah mengakui bahwa ada kekuatan diluar kekuasaan manusia. Pandangan seperti ini dikenal dengan animisme dan dinamisme. Mereka menyimbolkan Tuhan dengan berbagai bentuk rupa yang terdapat dalam alam raya ini, seperti batu, pohon (animisme) dan di lain pihak mereka memandang roh manusia mempunyai kekuatan (dinamisme). Oleh karena itu, mereka mengakui dan memercayai kekuasaan diluar dirinya yang dikenal dengan Tuhan. Dalam banyak pepatah, dan peribahasa orang Melayu selalu terungkap kepercayaan yang dalam dari orang Melayu mengenai Tuhan seperti: "Tegak alif lurus tabung, sejauh perjalanan pulang pada yang satu jua" (Suwardi, 1991; Thamrin, 2015).

Manusia yang taat akan menjadi manusia yang mampu mengendalikan diri dengan (akal dan pikirannya) untuk selalu berbuat baik dan bermanfaat bagi sesama, senantiasa mengingat penciptanya dan menghargai alam sekitarnya. Hal ini tercermin dalam tradisi tulisan masyarakat Melayu pada syair 'Gurindam Dua Belas' yang berbunyi antara lain:

Barangsiapa mengenal Allah

suruh dan tegahnya tiada ia menyalah

Barang siapa mengenal diri

maka telah mengenal akan Tuhan yang bahari 
Makna dari pasal dalam gurindam tersebut adalah bahwasannya seseorang yang telah kenal dengan Tuhannya, maka ia akan taat pada perintahnya serta pasrah akan ketetapan-Nya. Kemudian juga dinyatakan bahwa seseorang yang kenal dan tahu akan dirinya sendiri, maka ia akan tahu bahwa tugas sejatinya adalah untuk menunaikan amanah Tuhan: menjadi rahmat bagi semesta alam. Hal ini menunjukkan bahwa pandangan hidup dan alam pikiran orang Melayu dalam perspektif hubungan manusia dengan Tuhan selaras dengan spirit kehambaan yang telah peneliti uraikan dalam BAB III sebelumnya (Esram, 2010; Irianto, 2015; Suwardi, 1991). Hal tersebut sesuai dengan firman Allah dalam Surat Al-Anbiya ayat 107 yang berbunyi: "Dan tiadalah Kami mengutus kamu, melainkan untuk (menjadi) rahmat bagi semesta alam".

Konsep Hubungan Manusia dengan Sesama (Hablun Minannas). Manusia adalah makhluk individu sekaligus makhluk sosial. Manusia sebagai makhluk individu tidak bisa hidup sendirian akan tetapi hidup secara berkelompok. Kelompok manusia yang paling kecil disebut keluarga dan kelompok besar disebut masyarakat atau bangsa. Orang Melayu identik dengan ungkapanungkapan yang bermakna menunjukkan sikap hidup kemanusiaan, persatuan, musyawarah serta keadilan sosial (Esram, 2010; Suwardi, 1991). Hal ini yang akan menjadi pondasi terciptanya tatanan kehidupan yang ideal. Sebagaimana yang terdapat dalam pasal 'Gurindam Dua Belas' berikut ini:

Raja mufakat dengan menteri

Seperti kebun berpagarkan duri

Betul hati kepada raja

Tanda jadi sebarang kerja

Hukum adil atas rakyat

Tanda raja beroleh inayat

Pasal dalam gurindam tersebut memiliki makna jika raja bermufakat, seiya sekata, sejalan dengan para menterinya, hal tersebut diibaratkan seperti kebun berpagarkan duri, tiada sesuatu apapun yang dapat masuk ke dalam kebun tersebut. Jika memiliki rasa taat, patuh dan mengikuti titah raja, maka segala perintah akan terlaksana dengan sebaik mungkin. Hukum adil, tidak memihak dan semena-mena terhadap rakyat, itulah tanda raja akan mendapat pertolongan Allah (Esram, 2010). Pemimpin yang adil adalah yang dapat menciptakan iklim yang mendorong pelaksanaan agama yang wajar, sehingga setiap orang dapat melaksanakan tugas spiritualnya sebagai pemegang amanat Tuhan. Esensi tugas tersebut adalah untuk mengelola dan memakmurkan bumi. Hal ini tentu saja selaras dengan spirit kemanusiaan yang menyatakan bahwa manusia diciptakan untuk menjadi khalifah, untuk mengelola bumi dan memakmurkannya (Irianto, 2015). Hal ini seiring 


\section{Pandangan hidup dan ....}

Briando, B. \& Embi, M. A.

dengan firman Allah SWT dalam surat Al Baqarah ayat 30 yang berbunyi: "Sesungguhnya Aku hendak menjadikan seorang khalifah di muka bumi".

Konsep Hubungan Manusia dengan Alam (Hablun Minal Alam). Manusia dengan alam saling membutuhkan dalam kelangsungan hidupnya. Manusiaciptaan Tuhan, khususnya orang Melayu dalam menyampaikan pesan seperti terungkap dalam tradisi tulisan dan lisan selalu menggunakan gejala alam, dan isi alam. Hal ini tampak dalam ungkapan berikut:

Berbapak kelangit, Beribu ke bumi

Laut sakti, Rantau bertuah

Kecil laut, besar laut, laut juga namanya.

Tuah ayam terletak di kakinya

Tuah hamba sahaya tergantung pada tuannya

Tuah negeri ditentukan oleh rajanya.

Makna dari pribahasa tersebut adalah kalau seseorang mau bahagia, berusahalah sendiri, jangan menggantungkan nasib kepada orang lain. Sebab bila sudah menjadi hamba sahaya orang lain hidupnya akan tergantung kepada majikannya.

Menengok angin pada pohon

Melihat tingkah pada telatah

Artinya, dari gejala atau tanda, tergambar perbuatan seseorang sehingga dapat diketahui tabiat dan perangainya (Suwardi, 1991).

Alam gaib dan alam nyata merupakan dua wujud alam menurut pandangan orang Melayu. Pandangan tentang alam gaib merupakan pengakuan, kepercayaan tentang adanya kekuasaan di luar kekuasaan manusia. Kekuasaan itu sering pula dimanifestasikan kembali kepada gejala dan isi alam semesta tersebut (Suwardi, 1991). Alam nyata dengan segala wujudnya seperti bumi, dengan segala benda yang terdapat di atas dan di dalam perut bumi itu serta langit dan planet-planetnya, dipandang mempunyai fungsi dan perannya untuk kepentingan kehidupan manusia. Dalam perjalanan kehidupan itu, orang Melayu telah memberdayakan alam nyata sesuai dengan kebutuhannya. Lautan, daratan, hewan, serta tumbuhan digunakan untuk mencukupi berbagai kebutuhan hidupnya (Esram, 2010).

Orang Melayu memiliki pandangan bahwa kesalahan memanfaatkan sumber daya alam akan menimbulkan bencana. Dengan demikian dapat dikatakan bahwa mereka yang hidup dari sumber alam tanpa merusak alam itu sendiri inilah yang disebut sebagai "kearifan lingkungan", sebagai contohnya adalah dengan bercocok tanam secara berpindah-pindah. Sistem ini berupa siklus tahunan tertentu. Pemakaian tanah itu bukanlah melebar terus-menerus yang bisa menghabiskan area tanah. Tapi memperhitungkan kemampuan alam (hutan) dalam batas-batas yang wajar (Suwardi, 1991). Hal ini tentu saja selaras dengan spirit kesemestaan, yaitu nilai/ruh yang 
digunakan untuk menentukan baik buruknya dampak gagasan, aktivitas dan keilmuan terhadap situasi dan kondisi lingkungan alam sekitarnya (AhimsaPutra, 2016). Hal ini juga selaras dengan firman Allah SWT dalam Surat AlQashash ayat 77 yang berbunyi: "Janganlah kamu berbuat kerusakan di muka bumi. Sesungguhnya Allah tidak menyukai orang-orang yang berbuat kerusakan".

Konsep Manusia sebagai Makhluk Pribadi. Manusia senantiasa terdiri dari unsur jasad atau jasmani dan rohani atau jiwa. Kesatuan utuh dari manusia itu yang membedakannya dengan makhluk lain. Di dalam rohani manusia terdapat nafsu yang mendorong manusia untuk berbuat baik atau buruk. Pengendali nafsu menurut pandangan agama adalah iman dan taqwa. Manusia yang mampu mengendalikan kehendak berbuat buruk atau jahat akan terbentuklah manusia berkepribadian. Manusia dibekali dengan daya pikir dan perasaan. Kemampuan berpikir (cipta) dan pertimbangan melalui rasa dan karsa akan mewujudkan karyanya. Manusia perlu berhubungan dengan manusia lain (makhluk sosial) yang dapat menunjukkan kelebihan dan kekurangan manusia yang satu daripada manusia lainnya (Suwardi, 1991; Thamrin, 2015)

Setiap manusia mempunyai kemampuan internal yang berbeda dari seseorang dengan orang lainnya. Faktor eksternal (lingkungan) membentuk pula manusia itu. Dengan demikian manusia mempunyai watak, sikap dan tingkah laku tersendiri, sehingga dapat disebut manusia sebagai makhluk pribadi (Esram, 2010; Suwardi, 1991; Thamrin, 2015). Manusia sebagai pribadi memiliki daya pengendali dalam berbuat. Manusia yang mampu menggunakan daya pikir, emosi secara tepat dengan pertimbangan hati nuraninya disebut mempunyai kepribadian. Kepribadian itu yang dapat membedakan manusia yang satu dengan yang lain (Suwardi, 1991).

Pembentukan kepribadian manusia terutama dapat dilakukan melalui proses pendidikan, baik dalam sistem formal, non-formal maupun informal (Briando \& Purnomo, 2019). Proses pendidikan sebagai proses sosialiasi dalam kehidupan manusia mempunyai peranan besar pula terhadap pemahaman akan esensi manusia sebagai penuntut ilmu dalam mengenal Sang Pemilik Ilmu (Suwardi, 1991). Hal ini selaras pula dengan spirit kelimuan, penggunaan ilmu pengetahun didedikasikan hanya untukNya, dan bukan sebaliknya. Hal ini penting agar dalam menjalankan setiap aktivitas, tumbuh kesadaran bahwa segala sesuatu, termasuk ilmu yang diperoleh, esensinya hanyalah titipan Allah (Irianto, 2015).

Apabila setiap manusia dibekali dengan nilai-nilai, norma masyarakat yang baik maka manusia itu akan mempunyai kepribadian yang baik dan sebaliknya bila manusia itu dalam lingkungan yang buruk maka akan buruk pula kepribadiannya. Apabila dalam masyarakat terdapat manusia yang berkepribadian baik akan terwujud pula masyarakat yang berkepribadian baik (Esram, 2010; Suwardi, 1991). Pembentukan pribadi yang baik dapat 
dilakukan dengan menjaga anggota tubuh, sebagaimana bunyi gurindam berikut ini:

\section{Bersungguh-sungguh engkau memeliharakan tangan daripada segala berat dan ringan \\ Hendaklah peliharakan kaki \\ daripadanya berjalan yang membawa rugi}

Masyarakat Melayu dalam menjalani kesehariannya juga meyakini bahwa mereka diciptakan oleh Sang Pencipta tak lain dan tak bukan hanya untuk menyembah kepada-Nya. Di samping itu, kehidupan serta harga diri orang Melayu tidak terlepas dari pengaruh dan ajaran agama. Agama yang dianut orang Melayu sangat luas pengaruhnya dalam kehidupan sehari-hari. Karena ilmu agama memberikan acuan-acuan atau memberikan tuntunantuntunan dan ajaran-ajaran agar dapat hidup selamat baik di dunia maupun di akhirat. Dengan ajaran tersebut pula orang Melayu meyakini akan adanya kehidupan setelah manusia itu mati, dan menyadari bahwa segala tindak tanduk selama hidup di alam dunia akan dimintai pertanggungjawabannya kelak di alam akhirat.
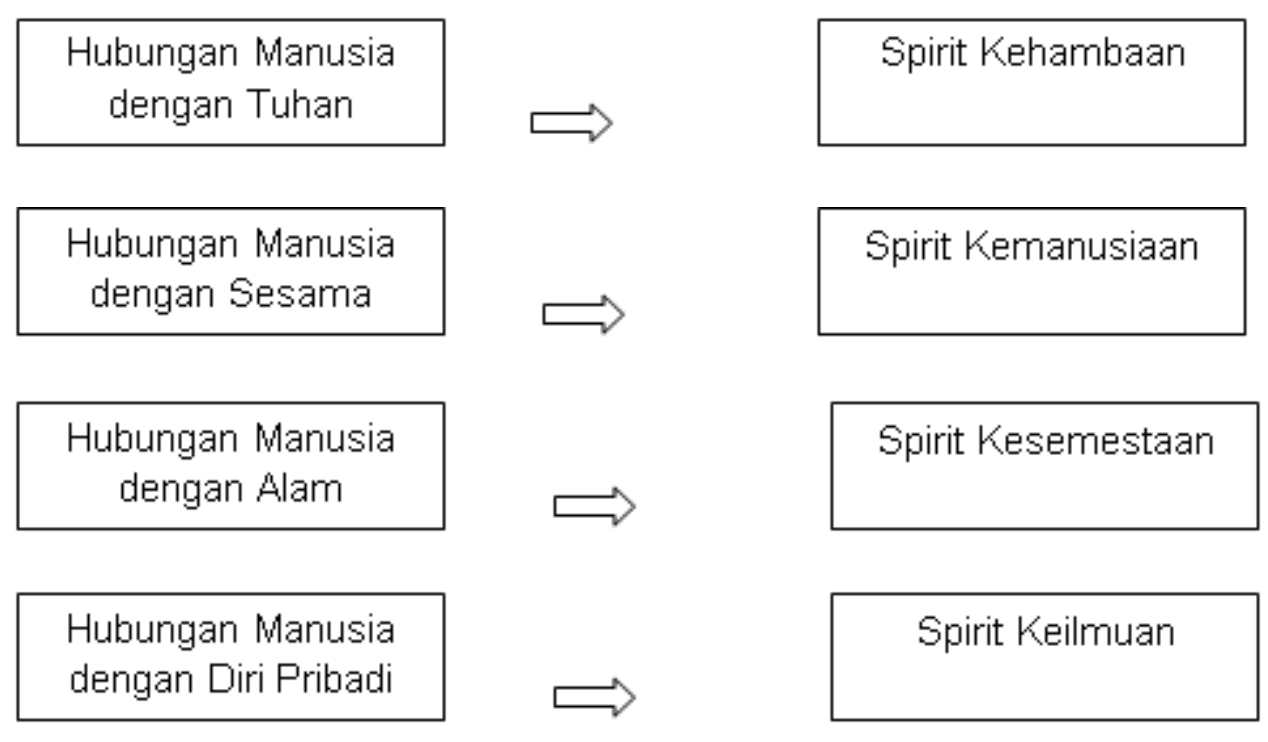

\section{Gambar 1. Relasi Konsep Pandangan Hidup}

Dari pandangan hidup dan alam pikiran orang Melayu yang telah peneliti utarakan di atas, peneliti berkesimpulan bahwa orang Melayu memiliki suatu penyadaran yang mendalam akan esensinya diciptakan di muka bumi sebagai makhluk ciptaan Tuhan yang memiliki kewajiban mengabdi kepada-Nya. Hal ini juga senada dengan apa yang diutarakan oleh informan yang mengatakan:

"Kita hidup di dunia ini tak lain dan tak bukan adalah sebagai khalifah, sebagai seorang khalifah, maka dalam mengemban suatu amanah segala 
sesuatunya harus kita kembalikan kepada apa yang menjadi perintahNya. Perintah tersebut tak lain adalah untuk mengabdi kepada-Nya. Menjalankan apa yang diperintahkan, serta menjauhi atas apa yang dilarang oleh-Nya agar kita dapat senantiasa berada di jalan yang lurus "ikhdinas shirotol mustaqim" sesuai dengan koridor yang telah ditetapkan".

Informan kemudian melanjutkan bahwa untuk berada di jalan yang lurus sebenarnya tidak sulit, seperti apa yang dinyatakan berikut ini:

Kita menuju "ihdinas shirotol mustaqim" itu, menuju jalan Allah tak sulit-sulit, gampang saja, pertama Hablun Minallah yang kedua Hablun Minannas. Kalau kedua hubungan tersebut senantiasa kita jaga dengan baik, ditambah kita peduli terhadap kelestarian lingkungan sekitar secara ikhlas semata karena Allah, ini sudah "selesai". Inilah "kunci" yang akan membuka "pintu" agar terbuka suatu "jalan yang lurus" bagi kita dalam menjalani kehidupan.

Inilah yang menjadi harapan bersama, alangkah indahnya jika setiap pribadi termasuk didalamnya pengelola keuangan memiliki kesadaran yang sama, yaitu kesadaran bahwa manusia sejatinya diciptakan oleh Allah untuk senantiasa mengabdi kepada-Nya. Dengan selalu menjaga hubungan yang intim dengan Allah SWT (Hablun Minallah), kemudian senantiasa menjaga hubungan harmonis dengan sesama manusia (Hablun Minannas), serta cinta terhadap lingkungannya (Hablun Minal Alam). Kesadaran tersebut yang akan menjadi "kunci" utama seseorang agar selalu berada di jalan yang lurus "ihdinas shirotol mustaqim".

\section{SIMPULAN}

Pandangan hidup merupakan sebuah kristalisasi dari nilai-nilai yang dimiliki dan diyakini kebenarannya sehingga menimbulkan tekad untuk dapat mewujudkannya. Kejeniusan lokal budaya Melayu dalam membentuk pribadi Orang Melayu dapat tervisualisasikan dari terbentuknya konsep pandangan hidup dan alam pikiran Orang Melay. Nilai-nilai luhur sejatinya harus dapat di angkat dan di eksplorasi untuk kemudian dijadikan suatu panduan dalam bersikap dan bertingkah laku, sehingga local foolness yang menganggap budaya lokal sebagai suatu kebodohan dengan sendirinya dapat terbantahkan. Nilai luhur Melayu sebagai suatu pandangan hidup (way of life) dapat dijadikan suatu pedoman dalam bertingkah laku dan bertindak, sehingga marwah Melayu tidak hanya menjadi slogan semata namun dapat diaplikasikan di kehidupan nyata. Namun demikian, penulisan artikel ini masih merupakan konsep awal dan dapat di eksplorasi lebih lanjut secara ilmiah untuk penelitian berikutnya. 


\section{DAFTAR PUSTAKA}

Ahimsa-Putra, H. S. (2016). Paradigma Profetik Islam: Epistemologi, Etos, dan Model. Yogyakarta: Gadjah Mada University Press.

Briando, B., \& Purnomo, A. S. (2019). ETIKA PROFETIK BAGI PENGELOLA KEUANGAN NEGARA. Jurnal Akuntansi Multiparadigma. https://doi.org/10.18202/jamal.2019.08.10020

Briando, B., Triyuwono, I., \& Irianto, G. (2017). Gurindam Etika Pengelola Keuangan Negara. Jurnal Akuntansi Multiparadigma, 8(1), 1-17.

Esram, J. (2010). Konsepsi Raja Ali Haji tentang Pemerintahan. Tanjungpinang: CV. Milaz Grafika.

Irianto, G. (2015). Spirit Profetik, Akuntan, dan Pencegahan Fraud. Pidato Pengukuhan Jabatan Guru Besar Dalam Bidang Ilmu Akuntansi Sektor Publik, 1-50.

Mulawarman, A. D. (2019). Jang Oetama yang Hidup. Oetoesan-Hindia: Telaah Pemikiran Kebangsaan, 1(1), 33-42.

Suwardi, M. (1991). Adat Melayu. Pekanbaru: Yayasan Penerbit MSI.

Thamrin, H. (2015). Enkulturasi Dalam Kebudayaan Melayu. Al-Fikra: Jurnal Ilmiah Keislaman, 14(1), 99-151.

Yusdita, E. E. (2019). Rencana Pembelajaran (untuk) Peradaban. OetoesanHindia: Telaah Pemikiran Kebangsaan, 1(1), 1-12. 